УДК 316.4.063

DOI: 10.12731/2077-1770-2017-4-348-363

\title{
КОГНИТИВНАЯ ПРОБЛЕМАТИКА В СОВРЕМЕННЫХ ИССЛЕДОВАНИЯХ СОЦИАЛЬНО-ИНТЕГРАТИВНЫХ ПРОЦЕССОВ (К ПОСТАНОВКЕ ВОПРОСА)
}

\section{Ковригина Г.Д.}

Цель. Проанализировать роль, значение и направления реализации когнитивной тематики в современных науках об обществе с точки зрения эвристичности данного подхода в исследованиях проблемы социальной интеграции.

Метод или методология проведения работы. При подготовке статьи были использованы сопоставительный анализ и обобщение с референиией кданным как теоретических, так ипрактических исследований.

Результаты. В современном обществознании, включающем социологию, антропологию, экономику, социальную психологию когнитивная проблематика занимает все более значительное место, что дает возможность исследовать социальные процессы на новом теоретико-методологическом уровне и в рамках действительной полидисчиплинарности. Серьезным эвристическим потенциалом обладает подход, учитывающий когнитивные факторы, и для исследования процессов соџиальной интеграчии или конъюнкиии, напрямую связанным с доминирующей в массовом сознании в конкретный исторический период поведенческой «схемой».

Область применения результатов. Выводы и результаты могут быть применены для теоретического обоснования и методологического оснащения дальнейших исследований различных сочиальных прочессов, включая сочиальную интеграчию. Закономерным будет и использование данных результатов в образовательной практике социально-гуманитарных направлений.

Ключевые слова: когнитивные факторы; общественные науки; полидисииплинарность; сочиальная интеграция. 


\section{COGNITIVE PROBLEM \\ IN THE MODERN STUDIES OF SOCIO-INTEGRAL PROCESSES (TO A FIRST APPROXIMATION)}

\section{Kovrigina G.D.}

Purpose. To analyze the role, significance and directions of realizing of cognitive themes in modern social sciences from the point of view of the applicability of this approach in studies of the problem of social integration.

Methodology. During the preparation of the article, comparative analysis and generalization used with reference to the data of both theoretical and practical studies.

Results. In modern social science, including sociology, anthropology, economics, social psychology, cognitive problems occupy an increasingly important place, which makes it possible to investigate social processes on a new theoretical and methodological level and within the framework of actual polydisciplinarity. A cognitive-based approach has an important heuristic potential for the study of processes of social integration, for those are directly related to a certain behavioral "scheme" dominant in the mass consciousness in a given historical period.

Practical implications. Conclusions and results could be applied to the theoretical substantiation and methodological equipment of further studies of various social processes, including social integration. It will be natural to use these results in the educational practice of social and humanitarian areas.

Keywords: cognitive factors; social sciences; polydisciplinarity; social integration.

Интегрированное, консолидированное состояние является априорной нормой и критическим условием выживания и развития сообщества. Строго говоря, другие значимые факторы, такие, как приспособление к окружающей среде, экономические практики, взаимоотношения народа и власти, безопасность внутренняя и внешняя - в своей конечной эффективности также обусловлены 
степенью консолидации сообществ и общества, в целом. То есть, солидарность, или неравнодушное отношение к собратьям, соплеменникам и согражданам - выступает залогом успешного социального воспроизводства социума во всех его ключевых сферах.

В этой связи, степень социальной интеграции или конъюнкции современного отечественного социума не может не вызывать тревогу - уровень взаимной нетерпимости достиг критических отметок, люди, имеющие вполне четкое представление о конструктивных нормах взаимодействия, отмечают доминирование в социальной фактичности норм обратных - деструктивных [5], а социальное самочувствие наших соотечественников продолжает характеризоваться эмоциями преимущественно негативного спектра [7].

Состояние общественных отношений в любом социуме определяется балансом тенденций социальной дизъюнкции и социальной конъюнкции. Обоим процессам соответствуют специфичные состояния массового сознания или «социального мозга», в котором в периоды дизъюнктивной доминанты преобладают когнитивные схемы, санкционирующие и легитимирующие процессы распада, в периоды же доминирования конъюнктивных тенденций начинают проявляться схемы, ориентированные на конструктивные практики и солидарность. На мой взгляд, в российском обществе на протяжении двух десятков лет преобладает дизъюнктивное состояние, когда общественные связи не распадаются в большей степени благодаря социальной инерции, нежели социальной политике консолидации. Периоды конъюнктивного состояния эпизодичны, спорадичны, недолговременны и всегда обусловлены ситуативно (сочинская олимпиада, «крымский консенсус», юбилей Победы в ВОВ, «санкции», и т.п.). Постоянно воспроизводящаяся практика, (подобно бихевиористской дуге «стимул-реакция-подкрепление»), имеет значительные шансы закрепиться в качестве рутинного, само собой разумеющегося паттерна. Если в массовом сознании россиян закрепится практика несолидарного и не взаимно-сберегающего поведения, это явится критическим фактором для самой жизнеспособности российского общества. 
Такого рода положение вещей ставит перед вызовом не только общество и власть, но и ту сферу, которая призвана рефлексировать по поводу общественных отношений и их особенностей - то есть, социальную науку. И здесь все более становится очевидным, что без углубленных исследований механизмов формирования социальных представлений, социальных смыслов, способов познания социальной реальности и реакций на неё, достаточно сложно как судить об истоках и причинах данных деструктивных явлений, так и определять возможности их преодоления. Решение задачи исследования глубинных структур общественного сознания или «социального мозга» россиян на предмет его конъюнктивного потенциала и дизъюнктивных рисков возможно, на мой взгляд, через междисциплинарность, включающую наработки по проблемам социальной интеграции и возможности такой области, как когнитивистика.

Когнитивная проблематика привлекает всё большее внимание в социальных науках, приходящих к признанию того, что сознание все-таки «формирует бытие», или, по крайней мере, находится с ним в постоянной взаимообусловливающей диахронной связи. Когнитивный подход уверенно прокладывает дорогу в экономической науке [4], в том числе - через синтез с институциональной теорией [2]. Строго говоря, такая разновидность последней, как неоинституционализм, уделяющий повышенное внимание стереотипам, ритуалам, традициям и символам, уже демонстрирует очевидные признаки влияния когнитивистики.

Ещё очевиднее это воздействие в исследованиях поведения на фондовых рынках, где настроение инвесторов напрямую обусловлено их представлениями о грядущем положении вещей. В самом общем виде эти исследования объединяются под термином «социономика», истоки которой восходят к Р. Эллиотту, сформулировавшему «волновой принцип» социальных процессов на основе наблюдений за финансовыми рынками, которые, согласно Эллиотту, подчиняются особому организующему закону самоповторения по определенному образцу, отражающему последовательность Фибоначчи [17]. В настоящее время наиболее полно и последовательно 
идеи волновой теории в социальной практике развиваются такими американскими учеными, как Р. Пречтер и Дж. Касти. Пречтер, являющийся автором термина «социономика», убежден в том, что те или иные векторы социального настроения и социального изменения определяются в людях бессознательным стадным инстинктом, импульс к которому производится лимбической системой мозга. Именно этот импульс определяет социальное настроение человека, и не зависит от внешнего воздействия. Последовательность Фибоначчи, фрактальные и спиральные феномены в биологии, человеческом восприятии и мышлении указывают, - по мнению Пречтера, на биологические основания феномена социального настроения, те или иные векторы которого «репрезентируют изменения в человеческих установках», определяя тем самым и «соответствующие изменения в истории и культуре» [26, с. 15]. По мнению Касти, «Социальное настроение определяет характер событий, которые более или менее вероятны в определенный временной промежуток. ... Что вероятно, и что нет в данный момент времени жестко обусловлено тем, как люди видят в этот период своё будущее» [12, с. 12].

Тем самым, экономисты жестко связали характеристики социального самочувствия с когнитивными факторами. Ими же обусловливается и такой «сугубо психологический» феномен, как эмпатия, являющаяся, согласно Д. Лернеру, главным условием, определяющим успех модернизационных процессов, поскольку создает для этого необходимые когнитивно-психологические предпосылки через идентификацию социальных акторов с новыми политическими лидерами и программами, новыми экономическими продуктами и современными социальными институтами [23].

Когнитивная социология и когнитивная антропология прямо постулировали в качестве основного своего предмета проблематику социальных представлений и социального познания. Первая исследует социальные основания и условия человеческого мышления. Условное начало этому направлению в социологии было положено работами А. Сикурела, исследовавшему связь языка и социального взаимодействия [13]. Впоследствии, данное направление получило 
развитие в работах таких авторов, как Р. Вутнау, К. Серуло, Э. Зерабевел, П. Димаджио и целого ряда других исследователей [15]. Характерно, что Зерабевел, в частности, стремится дистанцировать данное направление от психологии социального познания, поскольку «когнитивная социология имеет дело не только с познанием социальных объектов, но с социальными основаниями познания вообще» [36, с. 116]. Отметим, одновременно, что в социологии, ещё до работ Сикурела, когнитивная проблематика по факту присутствовала в таких направлениях, как символический интеракционизм (Дж.Г. Мид, Г.Дж. Блумер), феноменологическая социология (А. Шютц), её «расширение» в виде этнометодологии (Г. Гарфинкель), словом, в подходах, исходивших из постулирования решающей роли символов в формировании и поддержании целостности сообщества [6].

Культурная антропология также совершает естественный «дрейф» в сторону все большего внимания к когнитивным, символическим основаниям жизненных практик людей и народов, использующим самый широкий набор символических средств для репрезентации, сохранения, усиления и подтверждения ценностей и общепринятых убеждений их членов. По словам М. Л. Фостер, «Культурным символом выступает любое представление той или иной вещи или идеи посредством чего-то, относящегося к иному порядку. Любой символ имеет назначение, не связанное напрямую с его использованием здесь и сейчас, являющееся сущностным элементом его смысла, и это назначение связано с деятельностью группы и ее представлениями» $[19$, с. 81$]$.

С. Тайлер утверждает: «когнитивная реорганизация выступает абсолютно естественным трендом в антропологии, озабоченной, как и ряд других наук, проблемой структурных принципов, применяемых людьми, культурами и видами в процессе адаптации к их среде обитания» $[32$, с. 20$]$.

Э. Коэн рассматривает любую социальную организацию в качестве ментального конструкта, в котором сообщество структурируется и оформляется с помощью когнитивных практик - символов, ритуалов и границ [14]. 
Р. Парментер предпринял попытку методологического синтеза положений семиотики Ч. Пирса с базовыми принципами антропологии, доказывая важность исследования «семиотического упорядочивания жизни общества» [25].

Б. Шор в рамках «символической антропологии» анализирует «когнитивное картирование» социальных пространств, свойственное тем или иным народам, фиксируя в этом процессе «тотемические», «ритуальные», «культурные» и «естественные» символы, выступающие главными социально-психологическими маркерами формирующегося и поддерживаемого мировоззрения [31]. Нейролингвист Т. Дикон изучает принципы и алгоритмы развития базовых принципов языка с точки зрения филогенеза и эволюции мозга [16].

Наконец, активно доказывает эвристичность сочетания социальных наук и когнитивистики современный британский антрополог М. Блох, по мнению которого, у антропологии вообще нет другой альтернативы, кроме как инкорпорировать в полной мере подходы когнитивистики, во всей её полидисциплинарности, включая методы естественных наук, изучающих природу сознания и мышления [11]. Эти же позиции отстаивают и целый ряд других исследователей, в частности, Х. Уайтхаус, Дж. Лейдлоу, У. Маккоркл и другие $[33 ; 35]$.

Картина не будет хотя бы относительно полной, если не упомянуть такие, относящиеся к социальной проблематике, активно развивающиеся в рамках современной когнитивистики направления исследований, как изучение «когнитивных предубеждений», концепция «обыденного социального знания», концепция «ситуативного познания» и концепция «социального мозга». Все указанные направления тесно связаны, прежде всего, с психологической областью когнитивной науки. «Когнитивные предубеждения» (или «искажения» в распространенной отечественной версии) анализируются, в частности, в трудах С. Московичи и Ф. Бушини, пришедшим к выводам о том, что «неискаженные» сообщения, в основном, оказывают косвенное воздействие на массовое сознание и социальные представления [8]. 
Д. Канеман и А. Тверский исследовали роль когнитивных предубеждений в ситуациях принятия решений, то есть, выбора эвристик, в том числе - в условиях высокой неопределенности [21]. Э. Лофтус исследовала роль когнитивных предубеждений применительно к индивидуальной и социальной памяти, доказывая избирательность и предвзятость обеих [24]. Основания для «нормального» восприятия когнитивных предубеждений были заданы в трудах итальянского философа и логика Э. Агацци, доказывавшего, что «такие предубеждения - не что-то такое, от чего нам следует избавляться, а то, что является предварительным условием познания нами мира» [1, c. 60-61]. Другими словами, когнитивные «искажения»есть, в действительности, эволюционно возникшие рамки восприятия, формирующие и характер социального познания. Примерами такого рода являются, в частности, «предпочтительное суждение о своей группе», «эффект негативности» (заставляющий нас уделять приоритетное внимание сообщениям негативного плана), или «эффект большинства» (понуждающий нас присоединяться к коллективному действию или волеизъявлению).

Концепция «обыденного социального знания» относится к вопросу о «мудрости толп», или к тому, обладают ли сообщества достоверным знанием о социальном мире, в котором живут и действуют? Ф. Кейл, когнитивный психолог из Йельского университета, утверждает, что «понимание людьми устройства окружающего их мира существенно менее детально и гораздо более неточно, нежели они себе представляют» [22, с. 368], что не только не снижает, но, напротив, должно активизировать интерес когнитивной науки к исследованиям повседневного знания «обычных людей». По данным, полученным отечественными исследователями, «мудрость толп» вполне реальна. Она «является свойством агрегированных оценок и существует в некоторых ограниченных областях повседневного социального знания» [3, с. 16]. С данной концепцией явственно перекликаются теория «распределенного познания» Э. Хатчинса, постулирующая множественность познающих субъектов при решении одной когнитивной задачи [20], и теория «ситуативного по- 
знания», согласно которой всякое знание о социальном мире всегда ситуативно обусловлено. По выражению М. Уилсон, - «ситуативное познание является познанием, которое протекает в контексте соответствующих задаче входов (inputs) и выходов (outputs)» [34, c. 626]. Тем самым, данное видение также акцентирует внимание на средовой и эволюционной составляющих индивидуального и группового когнитивного процесса.

Наконец, концепция «социального мозга» сформировалась в контексте попыток локализовать участки мозга, отвечающие за социальное поведение. У данной концепции есть серьезные эмпирические основания. В частности, убедительно доказывается существование двух самостоятельных механизмов социального познания - компетентности, как «элементарного» понимания другого человека, и эмпатии, как способности к его эмоциональному восприятию [18]. Важным открытием является и экспериментальная фиксация существования «зеркальных нейронов», благодаря которым и возможна эмпатия, и, следовательно, социальная конъюнкция. Зеркальные нейроны реагируют сходным образом как на действия, так и на эмоции других людей, то есть, при наблюдении эмоций другого человека, активируются те же области мозга, которые были бы задействованы при реальном переживании нами данной эмоции [28]. По мнению У. Принца, это, возможно, обусловлено тем, что мозг использует одинаковый принцип кодирования как для восприятия, так и для планирования действий [27]. На мой взгляд, как минимум, это означает, что паттерны социального поведения также могут «отзеркаливаться». И если люди в повседневности встречают равнодушие и агрессию, они будут реагировать таким же образом уже потому, что так диктует наше нейробиологическое устройство. Но верно и обратное - солидарность и сочувствие должны находить подобный же отклик.

Что касается конкретной локализации, исследователи, в общем, сходятся во мнении о чрезвычайном значении для социального поведения таких участков, как префронтальные отделы коры головного мозга (prefrontal cortex) [29], височная кора (temporal cortices) [30], a 
также лобная кора как основа «модели психического». Заметим, что отечественной когнитивно-психологической науке присущ преимущественно взгляд на социальное познание, как неизбежно связанное с аффектом, интеллект рассматривается в связи с эмоциями - традиция, заданная культурно-историческим подходом Л.С. Выготского [9]. Концепция же «социального мозга» до известной степени редуцирует социальное поведение человека до элементарной формулы «стимул-реакция», при которой игнорируются средовые - культурные, исторические, и символические факторы формирования homo agens - «человека действующего». Даже самая точная локализация участков мозга, отвечающих за наше социальное поведение, оставит открытым вопрос о его мотивах и причинах того или иного его характера. Без учета средовых факторов и особенностей когнитивной практики, эти вопросы рискуют остаться без ответов.

Таким образом, когнитивная проблематика не просто торит себе дорогу в социальных науках, a, фактически, уже заняла в них значительное место, позволяя исследовать просоциальное поведение вообще, и социальную конъюнкцию, в частности, на новом теоретико-методологическом уровне и в рамках действительной полидисциплинарности. Остается надеяться, что и в отечественном обществознании когнитивный подход получит должное внимание. На мой взгляд, один из серьезных заделов в этом направлении сделан, в частности, в концепции нейросоциологии, развиваемой А.В. Шкурко, подчеркивающим необходимость «интегративного описания социальных процессов на разных уровнях: от макроуровневой организации общества до нейрофизиологических процессов» [10, с. 197]. Как представляется, такое интегративное видение является одним из наиболее эвристически обещающих направлений дальнейших исследований социальных феноменов, включая нескончаемый поиск ответа на классический вопрос - «что делает общество возможным?».

\section{Список литературы}

1. Агацци Э. Эпистемология и социальное: петля обратной связи // Вопросы философии. 2010. № 7. С. 58-66. 
2. Балацкий Е.В. Когнитивно-институциональный синтез Д. Норта // Общественные науки и современность. 2011. № 5. С. 154-166.

3. Девятко И.Ф., Абрамов Р.Н., Кожанов А.А. О пределах и природе дескриптивного обыденного знания о социальном мире // Социологические исследования. 2010. № 9. С. 3-17.

4. Каз М.С. Почему в экономических исследованиях необходим когнитивный подход? // Вопросы философии. 2009. № 4. С. 29-40.

5. Кармадонов О.А. Нормы и эмпатия как факторы социальных преобразований // Социологические исследования. 2012. № 4. С. 17-25.

6. Кармадонов О.А. Социология символа. М.: Academia, 2004. 352 с.

7. Кармадонов О.А., Надольная А.А. Социальное самочувствие и интеграция общества. Иркутск: Изд-во ИГУ, 2013. 179 с.

8. Московичи С., Бушини Ф. Являются ли предвзятые сообщения более эффективными, чем сообщения непредвзятые? // Психологический журнал. 2000. Т.21, №3. С. 20-32.

9. Рычкова О.В., Холмогорова А.Б. Концепция «социального мозга» как основы социального познания и его нарушений при психической патологии. Часть I. Концепция «Социальный мозг» - продукт современной нейронауки // Культурно-историческая психология. 2012. № 3. C. 86-94.

10. Шкурко А.В. На пути к нейросоциологии // Новые идеи в социологии / отв. ред. Ж.Т. Тощенко. М.: ЮНИТИ-ДАНАБ 2013. С. 184-200.

11. Bloch M. (2012) Anthropology and the Cognitive Challenge. Cambridge: Cambridge University Press. 234 p.

12. Casti J.L. (2010) Mood Matters. NY.: Springer Science+Business Media. $250 \mathrm{p}$.

13. Cicourel A. (1974) Cognitive Sociology: Language and Meaning in Social Interaction. New York: Free Press. 189 p.

14. Cohen A.P. (2000) The Symbolic Construction of Community. London: Routledge. $128 \mathrm{p}$.

15. Culture in Mind: Toward a Sociology of Culture and Cognition / ed. by Karen A. Cerulo. London: Routledge, 2002. 308 p.

16. Deacon T.P. (1997) The Symbolic Species: The Co-evolution of Language and the Brain. New York: W.W. Norton \& Company, Inc. 527 p. 
17. Elliott R.N. (1994) R.N. Elliott's Masterworks: the Definitive Collection. Gainesville, GA: New Classics Library. 308 p.

18. Fiske S.T., Cuddy, A.J.C., Glick, P. (2007) Universal Dimensions of Social Cognition: Warmth and Competence. Trends in Cognitive Sciences. N 11, pp. 1050-1057.

19. Foster M.L. (1990) Analogy, Language, and the Symbolic Process, in Foster, M.L. and Botscharow, L.J. (eds.) The Life of Symbols. Boulder: Westview Press. 318 p.

20. Hutchins E. (1995) Cognition in the Wild. Cambridge, MA: MIT Press. $380 \mathrm{p}$.

21. Kahneman D., Slovic P., Tversky A. (eds.) (1982) Judgment under uncertainty: Heuristics and biases. Cambridge, UK: Cambridge University Press. 452 p.

22. Keil F.C. (2003) Folkscience: Coarse Interpretations of a Complex Reality. Trends in Cognitive Sciences. Vol. 7. N 8, pp. 368-373.

23. Lerner D. (2000) The Passing of Traditional Society, in: Roberts, J.T., Hite, A. (eds.) From Modernization to Globalization: Perspectives on Development and Social Change. Oxford: Blackwell Publishers, pp. 119-134.

24.Loftus E.F. (2004) Memories of Things Unseen. Current Directions in Psychological Science. Vol. 13, pp. 145-147.

25. Parmentier R.J. (1994) Signs in Society: Studies in Semiotic Anthropology. Bloomington: Indiana University Press. 174 p.

26. Prechter R.R. (1999) The Wave Principle of Human Social Behavior and the New Science of Socionomics. Gainesville: New Classic Library. 463 p.

27. Prinz, W. Perception and Action Planning (1997). European Journal of Cognitive Psychology. N 9, pp. 129-154.

28. Rizzolatti G., Craighero L. (2004) The Mirror-Neuron System. Annual Review of Neuroscience. N 27, pp. 169-192.

29. Semendeferi K., Armstrong E., Schleicher A. et al. (2001) Prefrontal Cortex in Humans and Apes: a Comparative Study of Area 10. American Journal of Physical Anthropology. N 114, pp. 224-241.

30. Semendeferi K., Damasio H. (2000) The Brain and Its Main Anatomical Subdivisions in Living Hominoids Using Magnetic Resonance Imaging. Journal of Human Evolution. N 38, pp. 317-332. 
31. Shore B. (1996) Culture in Mind: Cognition, Culture, and the Problem of Meaning. New York: Oxford University Press. 428 p.

32. Tyler S.A. (1969) Cognitive Anthropology. New York: Holt, Rinehart and Winston, Inc. 179 p.

33. Whitehouse H., Laidlow, J. (2007) Religion, Anthropology, and Cognitive Science. Durham: Carolina Academic Press. 260 p.

34. Wilson, M. (2002) Six Views of Embodied Cognition. Psychonomic Bulletin \& Review. Vol. 9. N 4, pp. 625-636.

35.Xygalatas D., McCorkle W.W. (eds.) (2014) Mental Culture: Classical Social Theory and the Cognitive Science of Religion. London: Routledge. $268 \mathrm{p}$.

36.Zerubavel E. (1999) Social Mindscapes: an Invitation to Cognitive Sociology. Cambridge: Harvard University Press. 164 p.

\section{References}

1. Agazzi E. Epistemologiya i sotsial'noye: petlya obratnoy svyazi [Epistemology and social: feedback loop]. Voprosy filosofii [Issues of Philosophy]. 2010. N 7, pp. 58-66.

2. Balatsky E.V. Kognitivno-institutsional'nyy sintez D. Norta [Cognitive-institutional synthesis of D. North]. Obshchestvennyye nauki $i$ sovremennost' [Public science and modernity]. 2011. N 5, pp. 154-166.

3. Devyatko I.F., Abramov R.N., Kozhanov A.A. O predelakh i prirode de-skriptivnogo obydennogo znaniya o sotsial'nom mire [On the limits and nature of descriptive everyday knowledge of the social world]. Sotsiologicheskiye issledovaniya [Sociological Studies]. 2010. N 9, pp. 3-17.

4. Kaz M.S. Pochemu v ekonomicheskikh issledovaniyakh neobkhodim kogni-tivnyy podkhod? [Why does economic research require a cognitive approach?]. Voprosy filosofii [Issues of Philosophy]. 2009. N 4, pp. 29-40.

5. Karmadonov O.A. Normy i empatiya kak faktory sotsial'nykh preobra zovaniy [Norms and empathy as factors of social transformations]. Sotsiologicheskiye issledovaniya [Sociological Studies]. 2012. N 4, pp. 17-25.

6. Karmadonov O.A. Sotsiologiya simvola [Sociology of the symbol]. M.: Academia, 2004. 352 p. 
7. Karmadonov O.A., Nadol'naya A.A. Sotsial'noye samochuvstviye i integratsiya obshchestva [Social well-being and integration of society]. Irkutsk: Izd-vo IGU, 2013. 179 p.

8. Moskovici S., Buchini F. Yavlyayutsya li predvzyatyye soobshcheniya boleye effektivnymi, chem soobshcheniya nepredvzyatyye? [Are preconceived messages more effective than messages unbiased?]. Psikhologicheskiy zhurnal [Psychological Journal]. 2000. V. 21, N 3, pp. 20-32.

9. Rychkova O.V., Kholmogorova A.B. Kontseptsiya «sotsial'nogo mozga» kak osnovy sotsial'nogo poznaniya i yego narusheniy pri psikhicheskoy pato-logii. Chast' I. Kontseptsiya «Sotsial'nyy mozg» - produkt sovremennoy neyronauki [The concept of the "social brain" as the basis of social cognition and its violations in mental pathology. Part I. The concept "Social Brain" - a product of modern neuroscience]. Kul 'turno-istoricheskaya psikhologiya [Cultural and historical psychology]. 2012. N 3, pp. 86-94.

10. Shkurko A.V. Na puti k neyrosotsiologii [On the way to neurosociology]. Novyye idei $v$ sotsiologii [New ideas in sociology ]/ ed. ZH.T. Toshchenko. M.: YUNITI-DANA, 2013, pp. 184-200.

11. Bloch M. (2012) Anthropology and the Cognitive Challenge. Cambridge: Cambridge University Press. 234 p.

12. Casti J.L. (2010) Mood Matters. NY.: Springer Science+Business Media. $250 \mathrm{p}$.

13. Cicourel A. (1974) Cognitive Sociology: Language and Meaning in Social Interaction. New York: Free Press. 189 p.

14. Cohen A.P. (2000) The Symbolic Construction of Community. London: Routledge. $128 \mathrm{p}$.

15. Culture in Mind: Toward a Sociology of Culture and Cognition / Ed. by Karen A. Cerulo. London: Routledge, 2002. 308 p.

16. Deacon T.P. (1997) The Symbolic Species: The Co-evolution of Language and the Brain. New York: W.W. Norton \& Company, Inc. 527 p.

17. Elliott R.N. (1994) R.N. Elliott's Masterworks: the Definitive Collection. Gainesville, GA: New Classics Library. 308 p.

18. Fiske S.T., Cuddy A.J.C., Glick P. (2007) Universal Dimensions of Social Cognition: Warmth and Competence. Trends in Cognitive Sciences. N 11, pp. 1050-1057. 
19. Foster M.L. (1990) Analogy, Language, and the Symbolic Process, in Foster, M.L. and Botscharow, L.J. (eds.) The Life of Symbols. Boulder: Westview Press. 318 p.

20. Hutchins E. (1995) Cognition in the Wild. Cambridge, MA: MIT Press. $380 \mathrm{p}$.

21. Kahneman D., Slovic P., Tversky A. (eds.) (1982) Judgment under uncertainty: Heuristics and biases. Cambridge, UK: Cambridge University Press. 452 p.

22. Keil, F.C. (2003) Folkscience: Coarse Interpretations of a Complex Reality. Trends in Cognitive Sciences. Vol. 7. N 8, pp. 368-373.

23. Lerner D. (2000) The Passing of Traditional Society, in: Roberts J.T., Hite A. (eds.) From Modernization to Globalization: Perspectives on Development and Social Change. Oxford: Blackwell Publishers, pp. 119-134.

24.Loftus E.F. (2004) Memories of Things Unseen. Current Directions in Psychological Science. Vol. 13, pp. 145-147.

25. Parmentier R.J. (1994) Signs in Society: Studies in Semiotic Anthropology. Bloomington: Indiana University Press. 174 p.

26. Prechter R.R. (1999) The Wave Principle of Human Social Behavior and the New Science of Socionomics. Gainesville: New Classic Library. 463 p.

27. Prinz W. Perception and Action Planning (1997). European Journal of Cognitive Psychology. N 9, pp. 129-154.

28. Rizzolatti G., Craighero L. (2004) The Mirror-Neuron System. Annual Review of Neuroscience. N 27, pp. 169-192.

29. Semendeferi K., Armstrong E., Schleicher A. et al. (2001) Prefrontal Cortex in Humans and Apes: a Comparative Study of Area 10. American Journal of Physical Anthropology. N 114, pp. 224-241.

30. Semendeferi K., Damasio H. (2000) The Brain and Its Main Anatomical Subdivisions in Living Hominoids Using Magnetic Resonance Imaging. Journal of Human Evolution. N 38, pp. 317-332.

31. Shore B. (1996) Culture in Mind: Cognition, Culture, and the Problem of Meaning. New York: Oxford University Press. 428 p.

32. Tyler S.A. (1969) Cognitive Anthropology. New York: Holt, Rinehart and Winston, Inc. 179 p. 
33. Whitehouse H., Laidlow J. (2007) Religion, Anthropology, and Cognitive Science. Durham: Carolina Academic Press. 260 p.

34. Wilson, M. (2002) Six Views of Embodied Cognition. Psychonomic Bulletin \& Review. Vol. 9. N 4, pp. 625-636.

35.Xygalatas D., McCorkle W.W. (eds.) (2014) Mental Culture: Classical Social Theory and the Cognitive Science of Religion. London: Routledge. $268 \mathrm{p}$.

36.Zerubavel E. (1999) Social Mindscapes: an Invitation to Cognitive Sociology. Cambridge: Harvard University Press. 164 p.

\section{ДАННЫЕ ОБ АВТОРЕ}

Ковригина Галина Дмитриевна, кандидат философских наук, доцент

ФГБОУ ВО «Иркутский национальный исследовательский технический университет»

ул. Лермонтова, 83, Иркутск, Иркутская обл., 664074, Российская Федерация

kowrigina.galina2017@yandex.ru

\section{DATA ABOUT THE AUTHOR}

Kovrigina Galina Dmitrievna, $\mathrm{PhD}$, Associate Professor

Irkutsk National Research Technical University

83, Lermontov Str., Irkutsk, Irkutsk region, 664074, Russian Federation

kowrigina.galina2017@yandex.ru 